DOI: $10.17805 /$ zpu.2015.2.4

\title{
Особенности гражданско-патриотического воспитания студентов университета в современных условиях
}

\author{
О. А. ГАВРИЛЮК, А. Г. ЗОТИН, Е. С. КОНСТАНТИНОВА, Е. Г. ФОМИНА, Е. В. ШТАРК \\ (КРАСНОЯРСКИЙ ГОСУДАРСТВЕННЫЙ МЕДИЦИНСКИЙ УНИВЕРСИТЕТ \\ ИМ. ПРОФ. В.Ф. ВОЙНО-ЯСЕНЕЦКОГО)
}

Современные социальные, политические и экономические процессы в России обусловили значимость поиска нового содержания, новых форм и технологий гражданско-патриотического воспитания студентов российских университетов, чему и посвящено представленное исследование.

Исследование включает анализ научно-педагогической литературы по проблеме гражданско-патриотического воспитания студентов, наблюдение за воспитательным процессом и проведенный в 2014 г. опрос студентов с использованием специально разработанного опросника. В качестве опрошенных выступили студенты первого курса Красноярского государственного медицинского университета им. проф. В. Ф. Войно-Ясенецкого.

Результаты опроса показали невысокий уровень развития гражданско-патриотических качеств студентов-первокурсников одновременно с тем фактом, что большинство из них осознают значимость гражданско-патриотических качеств для врача. Полученные результаты также позволили выявить направления повышения эффективности работы в области гражданско-патриотического воспитания студентов. С учетом быстрых темпов распространения информационных технологий в высшем образовании одним из наиболее эффективных средств интенсификации гражданско-патриотического воспитания студентов вузов могут рассматриваться информационные технологии и сетевые коммуникации. Тем не менее в современных условиях ключевую роль в обеспечении эффективности гражданскопатриотического воспитания студентов на основе новых технологий имеют профессионализм и активная гражданская позиция преподавателей вуза, известных специалистов.

Ключевые слова: гражданско-патриотическое воспитание, патриотизм, высшее образование, студенты-медики, образовательная среда, ценности, информационные технологии.

\section{BВEАЕНИЕ}

$\mathrm{B}$ современной России проблема гражданско-патриотического воспитания молодежи становится все более актуальной. Это связано в первую очередь с произошедшим разрушением традиционно сложившейся в стране идеологической основы общественной жизни, процессом вестернизации, в том числе влиянием массовой культуры. Все это привело к деформированию прежних ценностных ориентаций, снижению социальной активности молодежи, распространению экстремистских настроений, «критицизму, отрицанию и очернительству прошлого, насаждению так называемой массовой культуры, пропаганде культа насилия, аморальности» (Богданов, Хутин, 2012: 123). Ситуация становится крайне опасной с учетом сложившейся за последние годы геополитической обстановки, которая требует высокого уровня гражданственности от каждого члена российского общества. Ведь, как справедливо утверждает А. И. Наумов, именно гражданственность «в условиях трансформационного контекста <..> позволяет минимизировать политические риски при реализации модели устойчивого развития» (Наумов, 2012: 151). При этом в основе конституирования гражданственности, по мнению исследователя, лежат механизмы гражданского обучения/воспитания (там же). Между тем традиционно сложившаяся в вузах система гражданско-патриотического воспитания молодежи не отвечает вызовам нового времени. Сказанное обусловливает актуальность проблемы развития новых форм и методов воспитания, поиска нового содержания и путей интенсификации гражданско-па- 
триотического воспитания в российских вузах. В задачи исследования входило изучение ценностных ориентаций и уровня гражданско-патриотических качеств студентов-медиков, а также выявление возможностей образовательной среды современного вуза в гражданско-патриотическом воспитании российской молодежи.

\section{МАТЕРИААЫ И МЕТОАЫ}

Исследование включало анализ педагогической литературы по проблеме гражданско-патриотического воспитания, наблюдение за практической организацией образовательного процесса в Красноярском государственном медицинском университете им. проф. В. Ф. Войно-Ясенецкого (далее - КрасГМУ) и проведение интернет-анкетирования студентов-медиков в ноябре 2014 г. В анкетировании приняли участие 206 студентов (78 юношей и 128 девушек) первого курса, из них 60 студентов, обучающихся по специальности « Аечебное дело», 45 студентов, обучающихся по специальности «Педиатрия», 48 студентов, обучающихся по специальности «Стоматология», 21 студент, обучающийся по специальности «Медицинская кибернетика», 17 студентов, обучающихся по специальности «Фармация», и 15 студентов, обучающихся по специальности «Клиническая психология». Большая часть респондентов была представлена студентами русской национальности (83\% опрошенных), студенты других национальностей составили 10\% от всего количества опрошенных. Зарубежные студенты - 7\%. Анкетирование студентов проводилось по оригинальной анкете, составленной сотрудниками Центра межкультурной коммуникации КрасГМУ, включающей 12 вопросов и 10 сформулированных ценностей, значимость которых студентам было предложено оценить.

\section{РЕЗУАБТАТЫ И ОБСУЖАЕНИЕ}

Анализ литературы по проблеме исследования и наблюдения за практической организацией образовательного процесса в вузе позволил выявить, во-первых, что «формирование гражданской позиции студентов представляет собой целенаправленный педагогический процесс взаимодействия преподавателей, студентов, представителей социальных организаций, обеспечивающий рефлексивное отношение студентов к обществу, государству и социально-политическим явлениям, которое проявляется в гражданском поведении, основанном на гражданских убеждениях и ценностях» (Федотова, Мирветалиева, 2009: 126-127). Возможность такого взаимодействия может быть обеспечена путем включения студентов в различные образовательные проекты (подготовка электронных обучающих материалов), участие в которых позволяет преобразовать образовательную среду вуза. В свою очередь, это «запускает сложный механизм восприятия образовательной среды как “своей” (Артюхина, 2007: 325), стимулируя более глубокое осознание студентами корпоративных и профессиональных ценностей.

Во-вторых, изучение литературных источников показало, что гражданско-патриотическое воспитание "рожденных у компьютера» студентов (digital natives) (Bennett, Maton, Kervin, 2008: 775) требует активного использования информационных технологий. Одним из примеров применения информационных технологий в этом отношении выступают корпоративные информационные системы, которые способны обеспечить доступ к актуальной информации, интерактивность и способствуют росту интереса студентов к проблемам национальной культуры, истории, а также «социальной (гражданской) культуры жизнедеятельности» (Капустина, 2003: 48). Практика показывает, что әффективность работы специального сайта отдельной кафедры по 
гражданско-патриотической тематике или общего корпоративного портала вуза в отношении гражданско-патриотического воспитания возрастает, если а) у каждого пользователя есть права на размещение информации и комментариев; б) присутствует реальная широкая вовлеченность членов образовательного сообщества вуза в обсуждаемые на сайте мероприятия. Именно эти принципы положены в основу работы корпоративного портала КрасГМУ (www.krasgmu.ru).

Анализ контента данного портала в отношении гражданско-патриотического воспитания студентов позволяет прийти к выводу о том, что в современных условиях реализация первого из названных выше принципов не представляет большой сложности. Реализация же второго принципа требует усилий со стороны преподавателей, кураторов, кафедр, студенческих организаций по развитию системы научных и творческих коллективов, строительных отрядов, волонтерских организаций, спортивных команд, обеспечивающих возможность общечеловеческого, нравственного воспитания студенческой молодежи в социально-культурной деятельности (Гладких, 2011: 154).

В образовательной среде современного вуза информационные технологии выступают не только средством реализации различных проектов гражданско-патриотической направленности, но и әффективным средством мониторинга работы в области гражданско-патриотического воспитания студентов. Тематические форумы на портале вуза позволяют выявить значимые для студентов ценности, их отношение к своей стране, языку. В рамках таких форумов могут быть обсуждены самые различные проблемы: от отношения молодежи к военной службе до перспектив русского языка и культуры русской речи. Особый интерес в этом отношении представляют международные форумы, на которых в рамках обсуждения, например, проблемы национальных стереотипов студенты не просто знакомятся с фактами иной культуры, но и проводят «переоценку фактов родной культуры» (Межкультурное ..., 2014: 44), что стимулирует их гражданскую активность. Интернет-викторины дают возможность не просто оценить, но и расширить знания студентов в области культуры, истории России, русского языка.

Изучение специальной литературы и практика работы в университете показывают, что особым потенциалом в отношении гражданско-патриотического воспитания молодежи обладают занятия по предметам гуманитарного цикла. Эти занятия могут быть проведены в форме конференций, круглых столов, творческих вечеров. Так, например, в рамках дисциплины «История России» в КрасГМУ в 2014 г. была проведена театрализованная конференция «Аень народного единства», которая объединила сразу несколько групп студентов и, по отзывам студентов, позволила им почувствовать дух и атмосферу праздника, а также гордость за свою страну. Особый интерес у студентов вызывают театрализованные погружения в различные периоды истории России, на которых выступления в роли тех или иных героев обеспечивают личностное восприятие студентами исторических событий. При этом эффективность организации работы студентов в рамках изучения гуманитарных дисциплин может быть обеспечена стимулированием самостоятельного творческого поиска обучающимися истины, создающего основу для их самоориентации как граждан (Аубицкий, 2007: 291).

Использование информационных технологий и сетевых средств коммуникации в процессе гражданско-патриотического воспитания молодежи предполагает владение педагогами методикой интеграции информационных технологий в учебный процесс (Бовтенко, 2000: 27). В современной ситуации, характеризующейся активной иностранной культурно-информационной экспансией в средствах массовой инфор- 
мации, особое значение приобретает умение педагогов грамотно выбирать информационные ресурсы, сосредоточивая внимание на тех материалах, где необходимая информация представлена наиболее полно и доступно, в соответствии с культурно-национальным, социальным опытом обучающихся.

Аля выявления реальной ситуации в области развития гражданско-патриотических качеств студентов приведем результаты анкетирования студентов КрасГМУ. Большинство опрошенных студентов всех специальностей называют среди наиболее значимых для них ценностей любовь к близкому человеку (средняя оценка - 9,2 из 10 возможных баллов), дружбу (8,7 из 10 возможных баллов), образование (8,6 из 10 возможных баллов), здоровье (8,5 из 10 возможных баллов) и духовное богатство (8,4 из 10 возможных баллов). Средняя оценка респондентами значимости для них их национальной принадлежности составила 6,63 из 10 возможных баллов. Значимых различий между ответами студентов с российским и зарубежным гражданством в отношении данного вопроса не отмечено. При этом были выявлены различия по полу: у юношей оценка значимости своей национальной принадлежности была выше, чем у девушек (6,9 и 6,4 из 10 возможных баллов соответственно). Большинство студентов испытывает патриотические чувства к России. Исследование выявило, что в среднем 93,7\% всех опрошенных студентов гордятся тем, что живут в России (97\%). Более половины опрошенных (62,6\%) отметили, что следят за информацией, касающейся внешней политики нашей страны, на телевидении (36\% из общего числа положительно ответивших на вопрос студентов) и в сети Интернет (67\% из общего числа положительно ответивших на вопрос студентов).

Анализ ответов студентов на вопрос о путях развития гражданских качеств позволил выявить, во-первых, понимание в студенческой среде значимости развития данных качеств (лишь 14\% студентов отметили, что развивать гражданско-патриотические качества студентов в вузе не обязательно). Во-вторых, наиболее эффективным средством гражданско-патриотического воспитания $26,4 \%$ обучающихся считают творческие мероприятия, 20,4\% опрошенных - занятия по гуманитарным дисциплинам, 14,1\% респондентов - специальные лекции и семинары, $25,1 \%$ студентов - размещение информации на сайте вуза, в социальных сетях.

Наконец, по мнению большинства студентов-медиков, наиболее важным фактором гражданско-патриотического воспитания выступают примеры патриотизма и ярко выраженная гражданская позиция со стороны сотрудников вуза, известных врачей. Безусловно, одним из таких примеров для современных студентов остается професcop В. Ф. Войно-Ясенецкий, чье имя носит вуз. Во время Великой Отечественной войны В. Ф. Войно-Ясенецкий сочетал учебный процесс с работой хирурга и консультанта в эвакогоспиталях города, спасая тысячи тяжелораненых солдат. Знакомство с историей жизни этого замечательного хирурга, священника, беззаветно любящего свою страну, несмотря на все лишения и тяготы жизни, является одним из наиболее значимых путей развития гражданско-патриотических качеств будущих врачей.

\section{ВЫВОАЫ}

Реалии сегодняшнего дня требуют новых подходов к организации работы в области гражданско-патриотического воспитания, способных заложить основы для позиционирования конкурентных преимуществ российского образования, консолидации общества и укрепления государства. Одним из наиболее эффективных средств гражданско-патриотического воспитания современных студентов медицинского вуза выступают информационные технологии. Между тем эффективность их использования 
напрямую зависит от степени подготовки преподавателя и его активной гражданскопатриотической позиции.

Выявленные при помощи интернет-анкетирования ценностные ориентации студентов медицинского вуза, с одной стороны, отражают недостаточную сформированность у них гражданско-патриотических качеств, с другой стороны, они адекватны юношескому возрастному периоду и соответствуют профессиональной ориентации студентов-медиков на здоровый образ жизни.

Как показало исследование студентов КрасГМУ, большинство опрошенных испытывают патриотические чувства к России и признают значимость развития гражданско-патриотических качеств у студентов российских медицинских вузов. Полученные результаты позволили выявить направления повышения эффективности работы в области гражданско-патриотического воспитания студентов, среди которых особое внимание следует уделить широкому использованию возможностей информационных технологий и социальных сетей.

\section{СПИСОК АИТЕРАТУРЫ}

Артюхина, А. И. (2007) Образовательная среда высшего учебного заведения как педагогический феномен (на материале проектирования образовательной среды медицинского университета) : дис. ... А-ра пед. наук. Волгоград. 377 с.

Бовтенко, М. А. (2000) Компьютерные средства обучения языку: современные возможности // Компьютерные инструменты в образовании. № 6. С. 25-37.

Богданов, А. П., Хутин, А. Ф. (2012) Патриотизм и гражданственность как факторы укрепления государства // Знание. Понимание. Умение. № 4. С. 123-127.

Гладких, В. В. (2011) Особенности реализации концепции гражданско-патриотического воспитания молодежи в поликультурной среде вуза // Вестник МГУКИ. № 3 (41). С. 154-157.

Аубицкий, В. В. (2007) Воспитание студенчества как основа мобилизации социально-гражАанских качеств и инициатив // Аичность. Культура. Общество. Т. 9. № 4(39). С. 288-298.

Капустина, 3. Я. (2003) Воспитание гражданственности в условиях обновляющейся России // Педагогика. № 9. С. 45-49.

Межкультурное иноязычное образование : лингводидактические стратегии и тактики : коллективная монография (2014) / отв. ред. Е. Г. Тарева. М. : Аогос. 232 с.

Наумов, А. И. (2012) Социально-философский аспект проблемы формирования гражданственности молодежи в контексте непрерывного образования // Образование через всю жизнь: непрерывное образование в интересах устойчивого развития : мат. 10-й юбилейной междунар. конф. : в 2 ч. / под ред. Н. А. Аобанова, В. Н. Скворцова. Вып. 10. СПб. : АГУ им. А. С. Пушкина. Ч. 1.372 с. С. $150-155$.

Федотова, Г. А., Мирветалиева, С. 3. (2009) Становление гражданской позиции студентов технического вуза. Великий Новгород: Новгородский гос. ун-т им. Ярослава Мудрого. 144 с.

Bennett, S. J., Maton, K. A., Kervin, L. K. (2008) The 'digital natives' debate: A critical review of the evidence // British Journal of Educational Technology. Vol. 39. No. 5. P. 775-786.

Аата поступления: 12.02.2015 2.

SOME FEATURES OF UNIVERSITY STUDENTS' CIVIC AND PATRIOTIC EDUCATION IN THE CURRENT CONTEXT

O. A. Gavrilyuk, A. G. Zotin, E. S. Konstantinova, E. G. Fomina, E. V. Shtark (V. F. VoINo-YASENETSKY KRASNOYARSK StATE MEDICAL UNIVERSITY)

Contemporary social, political and economic processes in the Russian Federation have determined the importance of searching for new content, forms and techniques to improve the civic and patriotic education of university students. 
The general aim of this study is to reveal core values and the level of civic consciousness and patriotism in first year medicine majors and to investigate the potential of modern educational environment in university students' civic and patriotic education.

Our study involved an analysis of recent scientific findings in the area of students' civic consciousness and patriotism, observations of the educational process as well as conducting a survey among the students of V. F. Voino-Yasenetsky Krasnoyarsk Medical University in 2014. The survey used a specially developed questionnaire.

According to the research results, the level of civic consciousness and patriotism in first year medicine majors is not very high, although most of them appreciate the importance of these qualities for doctors. The survey outcomes demonstrated some possible ways of intensifying civic and patriotic education for university students. Taking into account a very high IT penetration growth rate in higher education, information technology and network communication may be considered as a means of such intensification.

However, in the current context the faculty's professionalism and social activism remain crucial for successful civic and patriotic education of their students.

Keywords: civic and patriotic education, patriotism, higher education, medicine majors, educational environment, core values, information technology.

\section{REFERENCES}

Artiukhina, A. I. (2007). Obrazovatel' naia sreda vysshego uchebnogo zavedeniia kak pedagogicheskii fenomen (na materiale proektirovaniia obrazovatel' noi sredy meditsinskogo universiteta) [The educational environment of a higher education institution as a pedagogical phenomenon (A case study of the development of educational environment of a medical university)] : dis. ... Doctor of Pedagogy. Volgograd. 377 p. (In Russ.).

Bogdanov, A. P. and Khutin, A. F. (2012) Patriotizm i grazhdanstvennost' kak factory ukrepleniia gosudarstva [Patriotism and civic consciousness as factors of state consolidation]. Znanie. Ponimanie. Umenie, no. 4, pp. 123-127. (In Russ.).

Bovtenko, M. A. (2000) Komp'iuternye sredstva obucheniia iazyku: sovremennye vozmozhnosti [Computer-aided language teaching: contemporary developments]. Komp'iuternye instrumenty vobrazovanii, no. 6, pp. 25-37. (In Russ.).

Gladkikh, V. V. (2011) Grazhdansko-patrioticheskoe vospitanie molodezhi v polikul'turnoi srede vuza [Civic and patriotic education of the youth within a multicultural university environment]. Vestnik Moskovskogo gosudarstvennogo universiteta kul'tury i iskusstv, no. 3 (41), pp 154-157. (In Russ.).

Dubitskii, V. V. (2007) Vospitanie studenchestva kak osnova mobilizatsii sotsial'no-grazhdanskikh kachestv i initsiativ [Students' personality development as the foundation for mobilizing social and civic qualities and incentives]. Lichnost'. Kul'tura. Obsbchestvo, vol. IX, no. 4 (39), pp. 288-298. (In Russ.).

Kapustina, Z. Ya. (2003) Vospitanie grazhdanstvennosti v usloviiakh obnovliaiushcheisia Rossii [Civic consciousness development under Russia's contemporary transformation]. Pedagogika, no. 9, pp. 45-49. (In Russ.).

Mezbkul' turnoe inoiazychnoe obrazovanie : lingvodidakticheskie strategii i taktiki [Intercultural education in foreign language: Linguo-didactic strategies and tactics] (2014) / ed. by E. G. Tareva. Moscow, Logos Publ. 232 p. (In Russ.).

Naumov, D. I. (2012) Sotsial'no-filosofskii aspekt problemy formirovaniia grazhdanstvennosti molodezhi $\mathrm{v}$ kontekste nepreryvnogo obrazovaniia [Sociophilosophical aspect of the problem of youth's civic consciousness development within the context of lifelong learning]. In: Obrazovanie cherez vsiu zhizn': nepreryvnoe obrazovanie v interesakb ustoichivogo razvitiia [Education throughout life: Lifelong learning for sustainable development] : proceedings of the 10th anniversary international conference/ ed. by N. A. Lobanov and V. N. Skvortsov. Issue 10. St. Petersburg, Pushkin Leningrad State University Publ. Part 1. 372 p. Pp. 150-155. (In Russ.). 
Fedotova, G. A. and Mirvetalieva, S. Z. (2009) Stanovlenie grazbdanskoi pozitsii studentov tekbnicheskogo vuza [Building students' civic-mindedness at a polytechnical university]. Veliky Novgorod, Yaroslav-the-Wise Novgorod State University Publ. 144 p. (In Russ.).

Bennett, S. J., Maton, K. A. and Kervin, L. K. (2008) The 'digital natives' debate: A critical review of the evidence. British Journal of Educational Technology, vol. 39, no. 5, pp. 775-786.

Submission date: 12.02.2015.

Гаврилюк Оксана Александровна - кандидат педагогических наук, заведующая кафедрой латинского и иностранных языков Красноярского государственного медицинского университета им. проф. В. Ф. Войно-Ясенецкого. Адрес: 660022, Россия, г. Красноярск, ул. П. Железняка, А. 1. Тел.:+7 (391) 227-12-12. Эл. адрес: oksana.gavrilyuk@mail.ru

Зотин Алексей Геннадьевич - старший преподаватель кафедры латинского и иностранных языков Красноярского государственного медицинского университета им. проф. В. Ф. ВойноЯсенецкого. Адрес: 660022, Россия, г. Красноярск, ул. П. Железняка, д. 1. Тел.: +7 (391) 227-12-12. Эл. адрес: alekseygz@yandex.ru. Научный руководитель - д-р пед. наук, проф. Н. И. Пак.

Константинова Елена Сергеевна - старший преподаватель кафедры латинского и иностранных языков Красноярского государственного медицинского университета им. проф. В. Ф. ВойноЯсенецкого. Адрес: 660022, Россия, г. Красноярск, ул. П. Железняка, А. 1. Тел.: +7 (391) 227-12-12. Эл. адрес: elena15k@mail.ru. Научный руководитель - канд. пед. наук О. А. Гаврилюк.

Фомина Елена Геннадьевна - старший преподаватель кафедры латинского и иностранных языков Красноярского государственного медицинского университета им. проф. В. Ф. ВойноЯсенецкого. Адрес: 660022, Россия, г. Красноярск, ул. П. Железняка, д. 1. Тел.: +7 (391) 227-12-12. Эл. адрес: e_fomina_2013@rambler.ru. Научный руководитель — канд. пед. наук О. А. Гаврилюк.

Штарк Елена Владимировна - старший преподаватель кафедры философии и социально-гуманитарных наук Красноярского государственного медицинского университета им. проф. В. Ф. Войно-Ясенецкого. Адрес: 660022, Россия, г. Красноярск, ул. П. Железняка, д. 1. Тел.: +7 (391) 221-71-74. Эл. адрес: elenashtark@mail.ru. Научный руководитель - А-р филос. наук, доц. А. В. Зберовский.

Gavrilyuk Oksana Aleksandrovna, Candidate of Pedagogy, Chair, Department of Latin and Foreign Languages, V. F. Voino-Yasenetsky Krasnoyarsk State Medical University. Postal address: 1 P. Zheleznyak St., 660022 Krasnoyarsk, Russian Federation. Tel.: +7 (391) 227-12-12. E-mail: oksana.gavrilyuk@mail.ru

Zotin Aleksey Gennadievich, Senior Lecturer, Department of Latin and Foreign Languages, V. F. Voino-Yasenetsky Krasnoyarsk State Medical University. Postal address: 1 P. Zheleznyak St., 660022 Krasnoyarsk, Russian Federation. Tel.: +7 (391) 227-12-12. E-mail: alekseygz@yandex.ru. Research advisor: Doctor of Pedagogy, Professor N. I. Pak.

Konstantinova Elena Sergeevna, Senior Lecturer, Department of Latin and Foreign Languages V.F. Voino-Yasenetsky Krasnoyarsk State Medical University. Postal address: 1 P. Zheleznyak St., 660022 Krasnoyarsk, Russian Federation. Tel.: +7 (391) 227-12-12. E-mail: elena15k@mail.ru. Research advisor: Candidate of Pedagogy O. A. Gavrilyuk.

Fomina Elena Gennadievna, Senior Lecturer, Department of Latin and Foreign Languages, V. F. Voino-Yasenetsky Krasnoyarsk State Medical University. Postal address: 1 P. Zheleznyak St., 660022 Krasnoyarsk, Russian Federation. Tel.: +7 (391) 227-12-12. E-mail: e_fomina_2013@rambler.ru. Research advisor: Candidate of Pedagogy O. A. Gavrilyuk.

Shtark Elena Vladimirovna, Senior Lecturer, Department of Philosophy, Sociology and the Humanities, V. F. Voino-Yasenetsky Krasnoyarsk State Medical University. Postal address: 1 P. Zheleznyak St., 660022 Krasnoyarsk, Russian Federation. Tel.: +7 (391) 221-71-74. E-mail: elenashtark@ mail.ru. Research advisor: Doctor of Philosophy, Associate Professor A. V. Zberovsky. 